\title{
Endurance Time Is the Most Responsive Exercise Measurement in Idiopathic Pulmonary Fibrosis
}

\author{
Shinichi Arizono PhD, Hiroyuki Taniguchi MD PhD, Koji Sakamoto MD PhD, \\ Yasuhiro Kondoh MD PhD, Tomoki Kimura MD PhD, Kensuke Kataoka MD PhD, \\ Tomoya Ogawa MSc, Fumiko Watanabe MSc, Osamu Nishiyama MD PhD, \\ Koichi Nishimura MD PhD, Ryo Kozu PhD, and Kazuyuki Tabira PhD
}

\begin{abstract}
BACKGROUND: Although pulmonary rehabilitation (PR) has been reported to improve exercise capacity in patients with idiopathic pulmonary fibrosis, it is unknown which exercise measurement is the most responsive for evaluation of PR efficacy. The purpose of this study was to compare the responsiveness of 5 exercise measurements by evaluating the efficacy of PR in subjects with idiopathic pulmonary fibrosis. METHODS: We conducted a prospective observational study in which 53 subjects with idiopathic pulmonary fibrosis were enrolled. The PR group underwent a 10-week out-patient PR program. The control group was observed without any additional intervention, including PR. Five exercise measurements (endurance time [ET], peak work rate, peak oxygen consumption $\left[\dot{\mathrm{V}}_{\mathrm{O}_{2}}\right], 6$-min walk distance, and incremental shuttle walk distance) were evaluated at baseline and after 10 weeks. The effect size was used for the assessment of responsiveness. RESULTS: In each group, 24 subjects completed the 5 measurements at baseline and after 10 weeks. The changes in ET (PR: 181.6\%; control: $-\mathbf{8 . 2 \%}$ ), peak $\dot{\mathrm{V}}_{\mathrm{O}_{2}}$ (PR: 7.6\%; control: $\left.-5.4 \%\right)$, peak work rate (PR: 15.1\%; control: $-5.1 \%$ ), 6-min walk distance (PR: 6.0\%; control: $-3.8 \%$ ), and incremental shuttle walk distance (PR: $9.1 \%$; control: $-5.1 \%$ ) were significantly different between the groups after 10 weeks $(P<.05)$. In the PR group, ET showed the most striking improvement among the 5 measurements $(P<.05)$, and its effect size was as large as 2.96 , whereas those of the others were all < 0.5. CONCLUSIONS: ET is the most responsive exercise measurement for evaluating PR efficacy in patients with idiopathic pulmonary fibrosis. Key words: endurance time; idiopathic pulmonary fibrosis; pulmonary rehabilitation; exercise capacity; responsiveness. [Respir Care 2014;59(7):1108-1115. (c) 2014 Daedalus Enterprises]
\end{abstract}

\section{Introduction}

Idiopathic pulmonary fibrosis is a chronic progressive disorder with significant morbidity and mortality. ${ }^{1}$ Several

Dr Arizono, Mr Ogawa, and Ms Watanabe are affiliated with the Department of Rehabilitation, and Drs Taniguchi, Kondoh, Kimura, and Kataoka are affiliated with the Department of Respiratory Medicine and Allergy, Tosei General Hospital, Seto, Aichi, Japan. Drs Arizono and Tabira are affiliated with the Division of Health Science, Graduate School of Health Science, Kio University, Kita-katsurahi-gun, Nara, Japan. Drs Arizono is also affiliated with the School of Rehabilitation Sciences, Seirei Christopher University, Hamamatsu, Shizuoka, Japan. Dr Sakamoto is affiliated with the Department of Respiratory Medicine, Nagoya University Graduate School of Medicine, Nagoya, Aichi, Japan. Dr Nishiyama is affiliated with the Department of Respiratory Medicine and retrospective longitudinal studies suggest a median survival time of $2-3$ y from the time of diagnosis. ${ }^{1}$ Patients with idiopathic pulmonary fibrosis have significantly reduced exercise capacity as manifested by a reduced 6-min

\footnotetext{
Allergy, Kinki University School of Medicine, Osaka-sayama, Osaka, Japan. Dr Nishimura is affiliated with the Department of Pulmonary Medicine, National Center for Geriatrics and Gerontology, Obu, Aichi, Japan. Dr Kozu is affiliated with the Department of Rehabilitation Medicine, Nagasaki University Hospital, Nagasaki, Japan.

This study was partly supported by a grant to the Diffuse Lung Diseases Research Group from the Ministry of Health, Labor, and Welfare of Japan and by the nonprofit organization Medise in Japan. The authors have disclosed no conflicts of interest.
} 
walk distance (6MWD) and reduced maximum oxygen uptake $\left.\left(\dot{\mathrm{V}}_{\mathrm{O}_{2}}\right)\right)^{2,3}$

Exercise capacity is considered to be one of the most important outcome measurements in chronic lung diseases. In patients with idiopathic pulmonary fibrosis, poor exercise capacity indicates a poor prognosis, ${ }^{4}$ and a recent study demonstrated that exercise capacity contributes to physiologic function and health-related quality of life. ${ }^{5}$ Exercise capacity measurements have been utilized as a primary end point in several clinical trials for patients with idiopathic pulmonary fibrosis, although most of them failed to show positive results. ${ }^{6,7}$ Only pulmonary rehabilitation (PR) has successfully demonstrated improvement of exercise capacity. ${ }^{8,9}$

Exercise capacity in general has been evaluated in several ways, including field walk tests, such as the 6-min walk test (6MWT) and incremental shuttle walk test (ISWT), and cardiopulmonary exercise tests. In patients with COPD, several studies have reported that endurance time (ET) measured using a cycle ergometer test is reproducible and more responsive to interventions, including drug therapy, than measurements obtained with a maximal test. ${ }^{10,11}$ Moreover, a recent study evaluating the synergistic effect of drugs and PR successfully demonstrated an improvement of exercise capacity with ET as outcome. ${ }^{12}$ However, in patients with idiopathic pulmonary fibrosis, the responsiveness of ET as an exercise measurement has not been fully investigated. We hypothesized that ET would also be a more responsive exercise measurement in patients with idiopathic pulmonary fibrosis.

The purpose of the study was to compare the responsiveness of 5 exercise measurements by evaluating the efficacy of PR in subjects with idiopathic pulmonary fibrosis.

\section{Methods}

\section{Subjects}

Subjects were patients referred to the out-patient clinic of the Tosei General Hospital (Aichi, Japan) between June 2005 and May 2011. Inclusion criteria were (1) < 75 y old, (2) diagnosis of idiopathic pulmonary fibrosis, (3) shortness of breath on effort, and (4) stable clinical condition with no infection or exacerbation in the previous 3 months. Exclusion criteria were severe comorbid ill-

Correspondence: Hiroyuki Taniguchi MD PhD, Department of Respiratory Medicine and Allergy, Tosei General Hospital, 160 Nishioiwakecho, Seto, Aichi 489-8642, Japan. E-mail: taniguchi@tosei.or.jp.

DOI: $10.4187 /$ respcare.02674

\section{QUICK LOOK}

\section{Current knowledge}

Pulmonary rehabilitation (PR) has been shown to improve exercise tolerance in patients with COPD and chronic restrictive pulmonary disease. Measurement of increased exercise capacity is commonly performed using the 6-min walk test.

\section{What this paper contributes to our knowledge}

Following a 10-week out-patient PR program with subjects with idiopathic pulmonary fibrosis, endurance time (ET) using cycle ergometry was the most responsive exercise measurement. ET may be used to evaluate the success of PR.

nesses, collagen vascular diseases, and need for long-term oxygen therapy.

The diagnosis of idiopathic pulmonary fibrosis was made in accordance with the American Thoracic Society/European Respiratory Society statement ${ }^{13}$ using the following major criteria: (1) exclusion of other known causes of interstitial lung disease, (2) abnormal pulmonary function with restriction and impaired gas exchange, (3) bibasilar reticular abnormalities with minimum ground-glass opacities on high-resolution computed tomography, and (4) transbronchial lung biopsy or bronchoalveolar lavage showing no features to support an alternative diagnosis. Minor criteria included (1) $>50 \mathrm{y}$ old, (2) insidious onset of otherwise unexplained dyspnea on exercise, (3) duration of illness $>3$ months, and (4) bibasilar inspiratory crackles. All of the major and at least 3 of the 4 minor criteria had to be satisfied. For those with a surgical lung biopsy specimen showing usual interstitial pneumonia, only the major criteria were considered relevant.

At the time of the study, none of the subjects were current smokers. Informed consent was obtained from all who participated. This study was approved by the ethics committee of the Tosei General Hospital (approval No. 213).

\section{Study Design}

This was a prospective observational study in which subjects consented to evaluation with predetermined measurement schedules for 10 weeks. Fifty-three subjects with idiopathic pulmonary fibrosis who had undergone evaluation at diagnosis were included in this study. During their observational periods, 26 subjects who also consented to participate in a PR program were included in the PR group. The other 27 subjects, who were observed without any intervention, including PR or addition of new medicine, 
were included in the control group. Measurements were made at baseline, immediately following the 10-week PR program in the PR group, and 10 weeks after baseline in the control group.

\section{Assessment}

Subjects performed 4 exercise tests, including an incremental load ergometry test (ILET), a constant load ergometry test (CLET), a 6MWT, and an ISWT. With these 4 exercise tests, 5 exercise measurements were obtained as described below. Measurements of body anthropometry, pulmonary function tests, arterial blood gas tensions, grip strength, quadriceps force, and respiratory muscle force were also obtained.

\section{Pulmonary Function Tests}

Spirometry (Chestac-55V, CHEST MI, Tokyo, Japan) was performed according to published recommendations. ${ }^{14}$ The single-breath diffusing capacity for carbon monoxide was also measured. All values are expressed as a percentage of the predicted values reported by the Japan Society of Respiratory Diseases. ${ }^{15}$

\section{Muscle Strength Tests}

Quadriceps force was measured using a dynamometer (Cybex II, Lumex, Bayshore, New York). The peak torque (newton-meters) was measured in both legs during a maximum isokinetic knee extension maneuver with the hip in $90^{\circ}$ flexion. ${ }^{16}$ The highest value from at least 4 maneuvers for each leg was recorded. Grip strength was measured with a hydraulic hand dynamometer (Smedley Dynamometer, TTM, Tokyo, Japan). Peak grip strength (newtons) was assessed with each hand, with the shoulder and wrist in neutral position. The highest value of at least 3 maneuvers was recorded for each hand. All subjects underwent respiratory muscle testing to determine the maximum inspiratory pressure and maximum expiratory pressure. The former was measured at residual volume, and the latter was measured at near total lung capacity (Vitalopower KH101, CHEST MI) according to the method proposed by Black and Hyatt. ${ }^{17}$ The highest value from at least 3 maneuvers was recorded.

\section{Exercise Tests}

ILETs were performed on an electronically braked cycle ergometer (232CXL, Combi, Tokyo, Japan) in accordance with published guidelines ${ }^{18}$ to evaluate maximum exercise capacity and to determine the nature of the exercise limitation. Gas exchange and ventilatory variables were collected on a breath-by-breath basis using 8-breath averaging (Centaura-2, CHEST MI). The protocol required a 3-min unloaded phase followed by a 10 -watt/min stage at a pedaling rate of $60 \mathrm{rpm}$ until the subject could no longer continue because of severe dyspnea or leg fatigue. Maximum heart rate was determined using the R-R interval from a 12-lead electrocardiogram (CardioStar, Fukuda Denshi, Tokyo, Japan). Peak values were defined as the values averaged during the last $30 \mathrm{~s}$ of the highest work load achieved. Peak values for $\dot{\mathrm{V}}_{\mathrm{O}_{2}}$ and work rate during exercise were recorded. The anaerobic threshold was determined by the V-slope technique. Work efficiency (oxygen consumption during exercise) was determined as the ratio of $\dot{\mathrm{V}}_{\mathrm{O}_{2}}$ to work rate, which is the increase in $\dot{\mathrm{V}}_{\mathrm{O}_{2}}$ divided by the sum of the work loads (in watts) during exercise.

CLETs were performed to determine ET using the same cycle ergometer used for the incremental test. The protocol required 2 min of unloaded cycling followed by cycling at $60 \mathrm{rpm}$ with a work rate equivalent to $80 \%$ of the peak work rate obtained in the incremental test. ${ }^{10}$ The subjects continued cycling at the constant submaximal work load. They were stopped according to the same criteria as used in the ILET, and ET was measured. The same work rate was used to measure ET at the end of the PR program.

6MWTs were performed according to the American Thoracic Society statement. ${ }^{19}$ Subjects were instructed to walk as far as possible in a 50-m-long corridor in $6 \mathrm{~min}$. All subjects had performed at least one test prior to study entry for the purpose of excluding training effects. The total distance walked was recorded as the 6MWD. After 10 weeks, the number of subjects whose distance changed by the minimum important difference $(34 \mathrm{~m})$ of the $6 \mathrm{MWD}^{20}$ was counted.

ISWTs were performed in a 10-m course identified by 2 cones placed $0.5 \mathrm{~m}$ from each end point. ${ }^{21}$ All subjects had performed at least one test prior to study entry for the purpose of excluding training effects. The total distance walked was recorded as the incremental shuttle walk distance (ISWD).

Subjects were asked to rate their dyspnea and leg fatigue at the end of all tests using the modified Borg scale. Transcutaneous $\mathrm{S}_{\mathrm{pO}_{2}}$ was monitored throughout all tests by pulse oximetry (Pulsox-3Li, Minolta, Tokyo, Japan).

\section{Pulmonary Rehabilitation Program}

The program comprised twice weekly, supervised exercise training for a period of 10 weeks in the Department of Rehabilitation at Tosei General Hospital. ${ }^{8}$ The supervised 90-min sessions consisted of respiratory care, subject education, and endurance and strength training. Physical therapists supervised the subjects to confirm that they performed the endurance and strength training. Subjects performed supervised training on a braked cycle ergometer with target of $20 \mathrm{~min}$ of continuous cycling. The target intensity was $80 \%$ of peak work rate obtained from the 

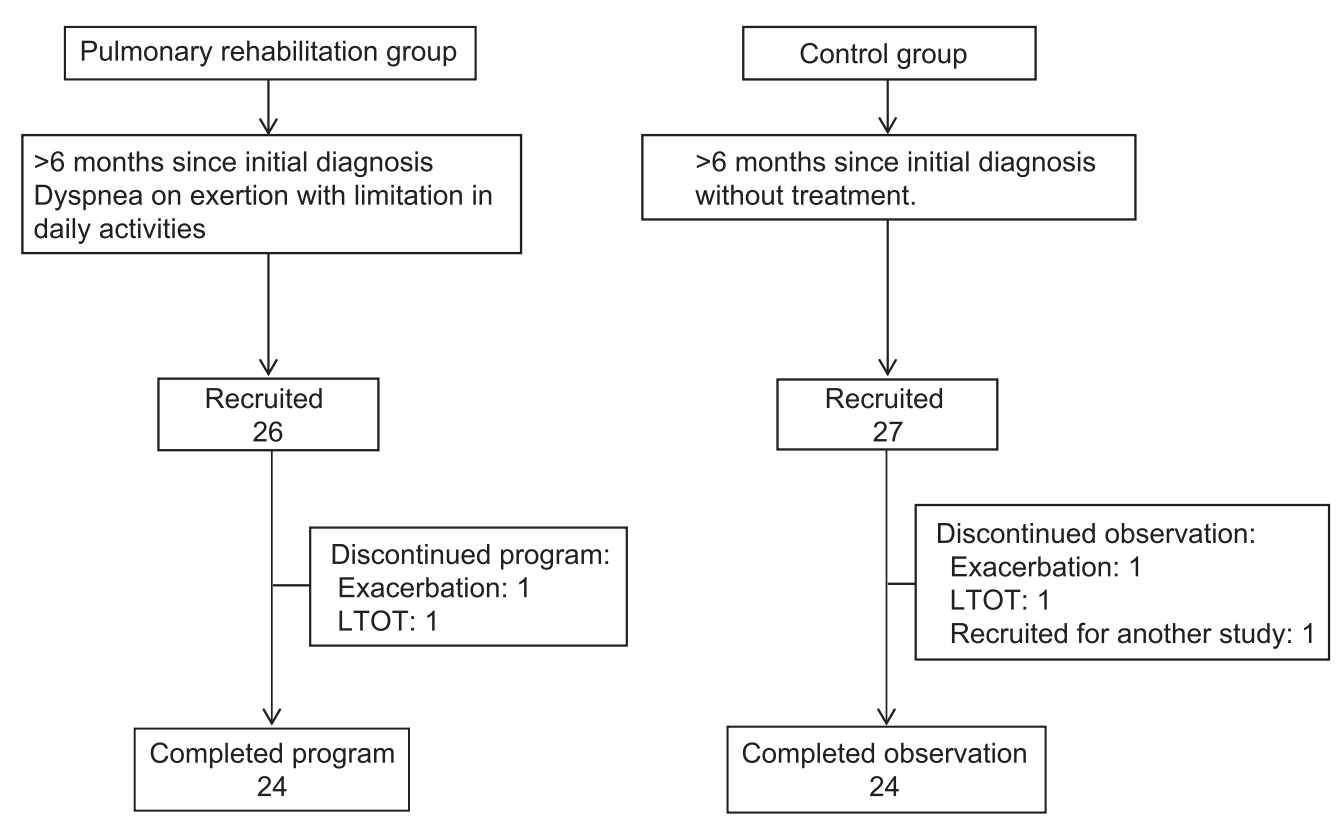

Fig. 1. Participant flow diagram. In the PR group, other indicates one patient received long term oxygen therapy due to severe hypoxia at rest. In the control group, other indicates one patient received long term oxygen therapy (LTOT) and one patient participated in another clinical trial study.

ILET. Subjects were monitored by pulse oximetry during endurance training. Peripheral muscle strength training included upper and lower limb resistance training with weight machines, hand weights, or elastic bands. Respiratory muscle training was performed using an inspiratory threshold device (Threshold IMT, Philips Respironics, Murrysville, Pennsylvania). The subjects trained with breathing at a resistance that required $30 \%$ of maximum inspiratory pressure for $15 \mathrm{~min}$. Subjects recorded the number of peripheral and respiratory muscle strength training sessions in a diary, and the diary was checked at each supervised session. If desaturation was $<80 \%$ during the CLET, subjects received oxygen therapy during exercise training. Supplemental oxygen was given to maintain $\mathrm{S}_{\mathrm{pO}_{2}}$ above $80 \%$ during exercise training.

\section{Statistical Analysis}

The baseline characteristics between the 2 groups were compared using unpaired $t$ tests. Differences in the values for each group before and after treatment were evaluated using the paired $t$ test. Change in outcome measurements was expressed as the percent change before versus after the program. Correlations between the change in the exercise measurements and muscle strength were assessed by Pearson analysis. The effect size evaluated responsiveness $^{22}$ and represented the mean change in the score divided by the SD of the baseline scores. Cohen ${ }^{23}$ suggested that effect sizes of $\geq 0.2$ to $<0.5$ indicate small changes, effect sizes of $\geq 0.5$ to $<0.8$ indicate moderate changes, and effect sizes of $\geq 0.8$ indicate large changes. The significance of the differences in the change observed in the 5 exercise measurements was determined with a repeated measures analysis of variance. When a significant difference was found, a post hoc analysis was performed with the Bonferroni adjustment method to identify which differences were significant. Changes in the outcome measurements between the 2 groups were compared using unpaired $t$ tests. $P<.05$ was considered significant. All data are given as mean $\pm \mathrm{SD}$. Analyses were performed using SPSS 17.0 (SPSS, Chicago, Illinois).

\section{Results}

Fifty-three patients were recruited to the study (Fig. 1). Twenty-six subjects were included in the PR group and began the PR program, and the 24 who completed the program underwent a second evaluation. In the control group, 27 subjects underwent baseline evaluation, and 24 of them underwent a second evaluation 10 weeks after baseline. In total, 48 subjects with idiopathic pulmonary fibrosis completed the study protocol and were enrolled in the subsequent analysis. Lung function data, arterial blood gas tensions, and exercise capacity at baseline were not different between the 2 groups (Table 1). In the PR group, 6 subjects received drug treatment during the study period: either prednisolone alone $(n=3)$ or prednisolone combined with cyclosporine $(n=3)$. In the control group, 3 subjects received drug treatment during the study period. Two subjects were treated with pred- 
Table 1. Lung Function and Arterial Blood Gas Tension Data at Baseline and After 10 Weeks

\begin{tabular}{|c|c|c|c|c|}
\hline & \multicolumn{2}{|c|}{ PR Group } & \multicolumn{2}{|c|}{ Control Group } \\
\hline & Baseline & $10 \mathrm{wk}$ & Baseline & $10 \mathrm{wk}$ \\
\hline Male/Female $(n)$ & $16 / 8$ & & $16 / 8$ & \\
\hline Age, (y) & $69.4 \pm 7.4$ & & $69.4 \pm 6.6$ & \\
\hline $\mathrm{VC},(\mathrm{L})$ & $2.08 \pm 0.75$ & $2.01 \pm 0.71$ & $2.22 \pm 0.68$ & $2.17 \pm 0.72$ \\
\hline $\mathrm{VC},(\%$ predicted $)$ & $70.8 \pm 18.1$ & $71.5 \pm 16.4$ & $75.7 \pm 16.0$ & $74.2 \pm 17.1$ \\
\hline $\mathrm{FEV}_{1},(\mathrm{~L})$ & $1.70 \pm 0.55$ & $1.72 \pm 0.53$ & $1.75 \pm 0.43$ & $1.73 \pm 0.48$ \\
\hline $\mathrm{FEV}_{1},(\%$ predicted $)$ & $82.9 \pm 19.5$ & $82.4 \pm 18.8$ & $85.5 \pm 18.2$ & $82.1 \pm 18.4$ \\
\hline $\mathrm{FEV}_{1} / \mathrm{FVC}$ & $0.84 \pm 0.08$ & $0.82 \pm 0.10$ & $0.82 \pm 0.10$ & $0.82 \pm 0.09$ \\
\hline $\mathrm{D}_{\mathrm{LCO}},(\mathrm{mL} / \mathrm{min} / \mathrm{mm} \mathrm{Hg})$ & $7.92 \pm 2.88$ & $7.98 \pm 2.93$ & $7.69 \pm 2.82$ & $7.67 \pm 2.77$ \\
\hline $\mathrm{D}_{\mathrm{LCO}},(\%$ predicted $)$ & $49.7 \pm 15.9$ & $49.8 \pm 18.4$ & $47.7 \pm 17.4$ & $47.4 \pm 16.5$ \\
\hline $\mathrm{P}_{\mathrm{aCO}_{2}}$ & $41.3 \pm 4.0$ & $41.0 \pm 4.4$ & $40.7 \pm 4.5$ & $41.7 \pm 5.6$ \\
\hline $\mathrm{P}_{\mathrm{aO}_{2}}$ & $79.6 \pm 9.9$ & $81.7 \pm 13.4$ & $78.6 \pm 15.1$ & $78.5 \pm 11.2$ \\
\hline \multicolumn{5}{|c|}{$\begin{array}{l}\text { Data are presented as mean } \pm \mathrm{SD} \\
\mathrm{PR}=\text { pulmonary rehabilitation } \\
\mathrm{VC}=\text { vital capacity } \\
\mathrm{D}_{\mathrm{LCO}}=\text { diffusing capacity of the lung for carbon monoxide }\end{array}$} \\
\hline
\end{tabular}

nisolone alone, and one subject was treated with sildenafil alone.

\section{Effects of the Rehabilitation Program}

In the PR group, 24 subjects completed 20 training sessions in the PR program. All subjects showed good adherence. The baseline characteristics of the 2 groups, together with their lung function data measured at baseline and after 10 weeks, are summarized in Table 1. Lung function and arterial blood gas tensions did change after 10 weeks in either group. Table 2 shows the muscle strength and exercise test data at baseline and after 10 weeks. In the PR group, the grip strength, quadriceps force, maximum expiratory pressure, and maximum inspiratory pressure improved significantly after 10 weeks. In the control group, measurements of muscle strength remained unchanged after 10 weeks. In the PR group, ET, peak work rate, anaerobic threshold, work efficiency, 6MWD, and ISWD improved significantly after 10 weeks $(P<.05)$, whereas peak $\dot{\mathrm{V}}_{\mathrm{O}_{2}}$ did not improve $(P=.19)$. In the control group, anaerobic threshold and work efficiency decreased significantly after 10 weeks $(P=0.009, P=0.04)$. In the PR group, the improvement of 10 subjects was greater than the minimum important difference for the 6MWD. In the control group, 8 subjects' results were less than the minimum clinically important difference for the 6MWD.

We further analyzed effect sizes of each measurement to assess responsiveness. In the PR group, a large effect size (2.96) was observed for ET, whereas small effect sizes $(<0.5)$ were observed for peak work rate, 6MWD, and ISWD. In the control group, all 5 measurements remained unchanged after 10 weeks.

The changes in peak $\dot{\mathrm{V}}_{\mathrm{O}_{2}}$ (PR: $7.6 \pm 22.7 \%$; control: $-5.4 \pm 16.5 \%, P=0.03)$, peak work rate (PR: $15.1 \pm 35.4 \%$; control: $-5.1 \pm 16.7 \%, P=0.02)$, ET (PR: $181.6 \pm 195.1 \%$; control: $-8.2 \pm 49.7 \%, P<0.001$ ), 6MWD (PR: $6.0 \pm 7.3 \%$; control: $-3.8 \pm 12.9 \%$, $P=0.002$ ), and ISWD (PR: $9.1 \pm 15.7 \%$; control: $-5.1 \pm 21.6 \%, P=0.01)$ were significantly different between the PR and control groups after 10 weeks (Fig. 2). In the PR group, ET showed the most striking improvement of the 5 exercise measurements, increasing by $181.6 \%$ $(P<.01)$.

For all 48 subjects, the changes in ET significantly correlated with changes in anaerobic threshold $(\mathrm{r}=0.50$, $P<0.01)$ and marginally significantly correlated with changes in work efficiency $(\mathrm{r}=0.28, P=.06)$. The changes in ET did not correlate with changes in muscle strength, including quadriceps force.

\section{Discussion}

The present study is the first to compare the responsiveness of 5 different exercise measurements in evaluating the effects of PR in subjects with idiopathic pulmonary fibrosis. We demonstrated that ET is the most responsive exercise measurement in subjects with idiopathic pulmonary fibrosis, as well as in subjects with COPD. The effect size of ET following PR was large compared with those of other exercise measurements. ET indicates submaximal exercise capacity. ${ }^{10}$ Peak $\dot{\mathrm{V}}_{\mathrm{O}_{2}}$ is the accepted standard for 
Endurance Time in Idiopathic Pulmonary Fibrosis

Table 2. Muscle Strength and Exercise Test Data at Baseline and Immediately Following Pulmonary Rehabilitation

\begin{tabular}{|c|c|c|c|c|c|c|}
\hline & \multicolumn{3}{|c|}{ PR Group } & \multicolumn{3}{|c|}{ Control Group } \\
\hline & Baseline & $10 w k$ & ES & Baseline & 10 wk & ES \\
\hline \multicolumn{7}{|l|}{ Muscle strength } \\
\hline Grip strength (newtons) & $270.7 \pm 94.2$ & $293.0 \pm 100.6^{*}$ & 0.24 & $277.3 \pm 88.2$ & $263.7 \pm 83.8$ & -0.15 \\
\hline Quadriceps force (newton-meters) & $83.1 \pm 30.3$ & $92.0 \pm 33.2 *$ & 0.29 & $82.6 \pm 25.3$ & $85.9 \pm 28.5$ & 0.13 \\
\hline $\mathrm{P}_{\mathrm{E}_{\max }}\left(\mathrm{cm} \mathrm{H}_{2} \mathrm{O}\right)$ & $141.1 \pm 53.3$ & $156.4 \pm 55.2^{*}$ & 0.29 & $139.0 \pm 42.8$ & $144.6 \pm 45.5$ & 0.13 \\
\hline $\mathrm{P}_{\mathrm{I}_{\max }}\left(\mathrm{cm} \mathrm{H}_{2} \mathrm{O}\right)$ & $111.5 \pm 36.8$ & $129.1 \pm 45.7^{*}$ & 0.48 & $92.1 \pm 41.1$ & $101.5 \pm 29.7$ & 0.23 \\
\hline \multicolumn{7}{|l|}{ ILET } \\
\hline Peak $\dot{\mathrm{V}}_{\mathrm{O}_{2}}(\mathrm{~mL} / \mathrm{min})$ & $651.7 \pm 294.2$ & $694.5 \pm 284.0$ & 0.12 & $743.1 \pm 255.0$ & $703.7 \pm 237.3$ & -0.20 \\
\hline Peak work rate (watts) & $60.8 \pm 24.4$ & $66.7 \pm 26.2 *$ & 0.24 & $65.9 \pm 17.1$ & $62.4 \pm 19.3$ & -0.21 \\
\hline Anaerobic threshold (mL/min) & $479.7 \pm 207.0$ & $585.4 \pm 277.5^{*}$ & 0.51 & $613.3 \pm 165.8$ & $520.0 \pm 149.0 *$ & -0.52 \\
\hline Work efficiency & $5.8 \pm 2.1$ & $6.4 \pm 2.7 \dagger$ & 0.29 & $6.9 \pm 2.0$ & $5.8 \pm 2.6 \dagger$ & -0.55 \\
\hline \multicolumn{7}{|l|}{ CLET } \\
\hline ET (min) & $5.7 \pm 3.1$ & $15.0 \pm 10.7 *$ & 2.96 & $6.5 \pm 5.5$ & $5.4 \pm 4.9$ & -0.16 \\
\hline \multicolumn{7}{|l|}{ 6MWT } \\
\hline 6MWD (m) & $477.7 \pm 91.0$ & $504.4 \pm 96.8^{*}$ & 0.29 & $499.4 \pm 66.6$ & $478.8 \pm 78.7$ & -0.31 \\
\hline \multicolumn{7}{|l|}{ ISWT } \\
\hline ISWD (m) & $365.6 \pm 119.7$ & $393.3 \pm 139.6^{*}$ & 0.26 & $393.5 \pm 116.3$ & $363.8 \pm 116.3$ & -0.20 \\
\hline $\begin{array}{l}\text { Data are presented as mean } \pm \mathrm{SD} \text {. } \\
* P<.01 \text { compared with baseline. } \\
\dagger P P<.05 \text { compared with baseline. } \\
\mathrm{PR}=\text { pulmonary rehabilitation } \\
\mathrm{ES}=\text { effect size } \\
\mathrm{P}_{\mathrm{E}_{\max }}=\text { maximum expiratory pressure } \\
\mathrm{P}_{\mathrm{I}_{\max }}=\text { maximum inspiratory pressure } \\
\mathrm{ILET}=\text { incremental load ergometry test } \\
\mathrm{V}_{\mathrm{O}_{2}}=\text { oxygen uptake } \\
\mathrm{CLET}=\text { constant load ergometry test } \\
\mathrm{ET}=\text { endurance time } \\
6 \mathrm{MWT}=\text { 6-min walk test } \\
6 \mathrm{MWD}=6 \text {-min walk distance } \\
\text { ISWT }=\text { incremental shuttle walk test } \\
\text { ISWD }=\text { incremental shuttle walk distance }\end{array}$ & & & & & & \\
\hline
\end{tabular}

exercise capacity. ${ }^{18}$ Peak work rate and ISWD indicate performance measurements of maximum exercise capacity. ${ }^{21}$ The 6MWD is a standard exercise measurement. ${ }^{19}$ The superiority of ET as a measurement of treatment efficacy has been studied in COPD. O'Donnell et $a^{11}$ reported that ET is both reproducible and responsive in evaluation of the efficacy of pharmacologic therapy in COPD. Oga et $\mathrm{al}^{10}$ found that ET was the most responsive test in detecting the effects of inhaled anticholinergic agents on exercise performance in subjects with stable COPD. We also recently reported that ET is the most responsive test for detecting the effects of PR in COPD patients. ${ }^{24}$ Considering the superiority of ET as shown in COPD, evaluation of ET in idiopathic pulmonary fibrosis in future trials may show the favorable effects of intervention more effectively.

In the present study, PR showed the largest increase in ET and moderately significant increases in peak work rate, 6MWD, and ISWD, but no significant change in peak $\dot{\mathrm{V}}_{\mathrm{O}_{2}}$. Two recent randomized controlled trials in subjects with idiopathic pulmonary fibrosis ${ }^{8}$ and interstitial lung disease $^{9}$ provide support for the benefits of PR. The effect of
PR was measured by the 6MWT, and modest benefits were observed. Kozu et $\mathrm{al}^{25}$ reported that PR produced smaller 6MWD improvements in subjects with idiopathic pulmonary fibrosis compared with patients with COPD. The 6MWD may reflect the maximum exercise capacity, as do peak work rate and ISWT. ${ }^{26,27}$ On the other hand, ET measures the ability to sustain submaximal exercise capacity. ${ }^{10}$ ET can improve even if there is no significant increase in maximum exercise capacity. ${ }^{10,28}$

In this study, ET and anaerobic threshold were improved significantly after PR in subjects with idiopathic pulmonary fibrosis. The changes in ET were significantly correlated with changes in anaerobic threshold. It is possible that, in subjects with idiopathic pulmonary fibrosis, PR also reduced exercise-induced lactic acidosis and increased oxidative enzymes in the peripheral muscles, which would have contributed to the improvement in ET. Work efficiency was improved significantly after PR in subjects with idiopathic pulmonary fibrosis. There was a weak association between the change in work efficiency and the change in ET. Low work efficiency often indicates inadequate oxygen transport during exercise and contributes to 


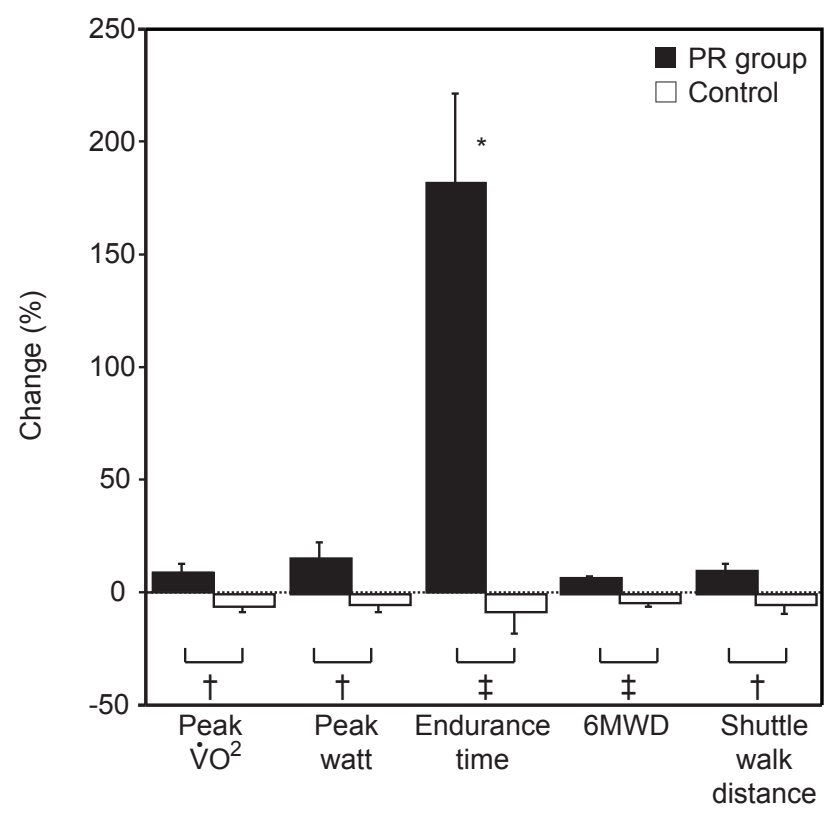

Fig. 2. Changes in various measurements of exercise capacity in 4 exercise tests after 10 weeks. $\dagger: P<.05$ compared with the control group. $\ddagger: P<.01$ compared with the control group. *: $P<.01$ compared with all measurements in the pulmonary rehabilitation (PR) group. $\left[\dot{\mathrm{V}}_{\mathrm{O}_{2}}\right]=$ oxygen uptake. $6 \mathrm{MWD}=$ six-minute walk distance.

exercise intolerance in pulmonary diseases. ${ }^{18,29} \mathrm{PR}$ may improve inadequate oxygen transport in patients with idiopathic pulmonary fibrosis. Improvement in oxygen transport may be related to improvement in ET in patients with idiopathic pulmonary fibrosis, as well as patients with COPD. ${ }^{24}$ The improvement in ET was not influenced by the improvement in muscle strength, such as quadriceps force. In patients with idiopathic pulmonary fibrosis, the mechanism of the improvement in ET and muscle strength may be different from that in patients with COPD.

There are several limitations to the present study. First, it remains uncertain whether the difference in responsiveness observed in this study is also true for other interventions, such as medication. We believe that several measurements should be assessed simultaneously in future trials that aim to improve exercise capacity. Second, this study was not randomized to assign subjects with idiopathic pulmonary fibrosis to the PR and control groups. Selection bias may be present between treatment groups. However, the main result that ET was the most responsive measurement was not seriously influenced by this issue. Third, ventilatory gas analysis, such as $\dot{\mathrm{V}}_{\mathrm{O}_{2}}$ during CLET, was not performed. Fourth, the number of subjects was small for a comparison of the responsiveness of 5 exercise measurements. Finally, we did not evaluate the long-term effects of PR in subjects with idiopathic pulmonary fibrosis.

In conclusion, our study showed that the 5 measurements obtained by 4 different exercise tests examined had different capabilities in detecting changes produced by PR in exercise performance in subjects with idiopathic pulmonary fibrosis. ET assessed by CLET showed the largest increase after PR, and it was considered to be the most responsive exercise measurement for evaluating PR efficacy in subjects with idiopathic pulmonary fibrosis.

\section{REFERENCES}

1. Raghu G, Collard HR, Egan JJ, Martinez FJ, Behr J, Brown KK, et al. An official ATS/ERS/JRS/ALAT statement: idiopathic pulmonary fibrosis: evidence-based guidelines for diagnosis and management. Am J Respir Crit Care Med 2011;183(6):788-824.

2. Eaton T, Young P, Milne D, Wells AU. Six-minute walk, maximal exercise tests: reproducibility in fibrotic interstitial pneumonia. Am J Respir Crit Care Med 2005;171(10):1150-1157.

3. Nishiyama O, Taniguchi H, Kondoh Y, Kimura T, Ogawa T, Watanabe F, Arizono S. Quadriceps weakness is related to exercise capacity in idiopathic pulmonary fibrosis. Chest 2005;127(6):20282033.

4. Lederer DJ, Arcasoy SM, Wilt JS, D’Ovidio F, Sonett JR, Kawut SM. Six-minute-walk distance predicts waiting list survival in idiopathic pulmonary fibrosis. Am J Respir Crit Care Med 2006;174(6): 659-664.

5. du Bois RM, Weycker D, Albera C, Bradford WZ, Costabel U, Kartashov A, et al. Six-minute-walk test in idiopathic pulmonary fibrosis: test validation and minimal clinically important difference. Am J Respir Crit Care Med 2011;183(9):1231-1237.

6. Idiopathic Pulmonary Fibrosis Clinical Research Network, Zisman DA, Schwarz M, Anstrom KJ, Collard HR, Flaherty KR, Hunninghake GW. A controlled trial of sildenafil in advanced idiopathic pulmonary fibrosis. N Engl J Med 2010;363(7):620-628.

7. King TE Jr, Behr J, Brown KK, du Bois RM, Lancaster L, de Andrade JA, et al. BUILD-1: a randomized placebo-controlled trial of bosentan in idiopathic pulmonary fibrosis. Am J Respir Crit Care Med 2008;177(1):75-81.

8. Nishiyama O, Kondoh Y, Kimura T, Kato K, Kataoka K, Ogawa T, et al. Effects of pulmonary rehabilitation in patients with idiopathic pulmonary fibrosis. Respirology 2008;13(3):394-399.

9. Holland AE, Hill CJ, Conron M, Munro P, McDonald CF. Short term improvement in exercise capacity and symptoms following exercise training in interstitial lung disease. Thorax 2008;63(6):549-554.

10. Oga T, Nishimura K, Tsukino M, Hajiro T, Ikeda A, Izumi T. The effects of oxitropium bromide on exercise performance in patients with stable chronic obstructive pulmonary disease. Am J Respir Crit Care Med 2000;161(6):1897-1901.

11. O'Donnell DE, Lam M, Webb KA. Measurement of symptoms, lung hyperinflation, and endurance during exercise in chronic obstructive pulmonary disease. Am J Respir Crit Care Med 1998;158(5 Pt 1): 1557-1565.

12. Casaburi R, Kukafka D, Cooper CB, Witek TJ Jr, Kesten S. Improvement in exercise tolerance with the combination of tiotropium and pulmonary rehabilitation in patients with COPD. Chest 2005; 127(3):809-817.

13. American Thoracic Society, European Respiratory Society. American Thoracic Society/European Respiratory Society international multidisciplinary consensus classification of the idiopathic interstitial pneumonias. Am J Respir Crit Care Med 2002;165(2):277-304.

14. American Thoracic Society. Standardization of spirometry: 1994 update. Am J Respir Crit Care Med 1995;152(3):1107-1136.

15. Japan Society of Chest Diseases. [The predicted values of pulmonary function testing in Japanese]. Jpn J Thorac Dis 2001;39:1-17 (Appendix). Article in Japanese. 


\section{Endurance Time in Idiopathic Pulmonary Fibrosis}

16. Watanabe F, Taniguchi H, Sakamoto K, Kondoh Y, Kimura T, Kataoka K, et al. Quadriceps weakness contributes to exercise capacity in nonspecific interstitial pneumonia. Respir Med 2013;107(4): 622-628.

17. Black LF, Hyatt RE. Maximal respiratory pressures: normal values and relationships to age and sex. Am Rev Respir Dis 1969;99(5): 698-702.

18. American Thoracic Society, American College of Chest Physicians. ATS/ACCP statement on cardiopulmonary exercise testing. Am J Respir Crit Care Med 2003;167(2):211-277.

19. ATS Committee on Proficiency Standards for Clinical Pulmonary Function Laboratories. ATS statement: guidelines for the six-minute walk test. Am J Respir Crit Care Med 2002;166(1):111-117.

20. Holland AE, Hill CJ, Conron M, Munro P, McDonald CF. Small changes in six-minute walk distance are important in diffuse parenchymal lung disease Respir Med 2009;103:1430-1435.

21. Singh SJ, Morgan MD, Scott S, Walters D, Hardman AE. Development of a shuttle walking test of disability in patients with chronic airways obstruction. Thorax 1992;47(12):1019-1024.

22. Jones PW, Harding G, Wiklund I, Berry P, Tabberer M, Yu R, Leidy NK. Tests of the responsiveness of the COPD assessment test following acute exacerbation and pulmonary rehabilitation. Chest 2012; 142(1): 134-140

23. Cohen J. Statistical power analysis for the behavioural sciences, 2nd edition. New York: Lawrence Erlbaum Associates; 1988.
24. Arizono S, Taniguchi H, Nishiyama O, Kondoh Y, Kimura T, Kataoka $\mathrm{K}$, et al. Improvements in quadriceps force and work efficiency are related to improvements in endurance capacity following pulmonary rehabilitation in COPD patients. Intern Med 2011;50(21):2533-2539.

25. Kozu R, Senjyu H, Jenkins SC, Mukae H, Sakamoto N, Kohno S. Differences in response to pulmonary rehabilitation in idiopathic pulmonary fibrosis and chronic obstructive pulmonary disease. Respiration 2011;81(3):196-205.

26. Swinburn CR, Wakefield JM, Jones PW. Performance, ventilation, and oxygen consumption in three different types of exercise test in patients with chronic obstructive lung disease. Thorax 1985;40(8): 581-586.

27. Luxton N, Alison JA, Wu J, Mackey MG. Relationship between field walking tests and incremental cycle ergometry in COPD. Respirology 2008;13(6):856-862

28. Porszasz J, Emtner M, Goto S, Somfay A, Whipp BJ, Casaburi R. Exercise training decreases ventilatory requirements and exerciseinduced hyperinflation at submaximal intensities in patients with COPD. Chest 2005;128(4):2025-2034.

29. Akkerman M, van Brussel M, Hulzebos E, Vanhees L, Helders P, Takken T. The Oxygen Uptake Efficiency Slope: what do we know? J Cardiopulm Rehabil Prev 2010;30:357-373.

29. Mainguy V, Maltais F, Saey D, Gagnon P, Martel S, Simon M, Provencher S. Peripheral muscle dysfunction in idiopathic pulmonary arterial hypertension. Thorax 2010;65(2):113-117. 